\title{
Emotion maps
}

\author{
William Cartwright* \\ RMIT University, william.cartwright@rmit.edu.au \\ * Corresponding author
}

Keywords: Maps, Art, Emotion

Themes: T1. Art and Cartography, T13. Map Design

\begin{abstract}
:
My perspective of Emotion Maps is not maps of emotions or the emotions evoked by spaces mapped or by mapping emotions evoked through the process of moving through a space. But - it is what we experience as 'emotional uplifting', when we view a cartographic artefact, whereby we elevate that artefact from a tool to communicate about geography to a piece of art. This is based on the premise of 'Emotional Architecture' proposed by by Mathias Goéritz in 1953 to describe an architecture elevated to art for the purpose of inspiring emotion (Loiseau, 2017). This led me to thinking about whether there are any maps that also inspire emotion.
\end{abstract}

As rightly noted by a reviewer of this contribution (and thank you to reviewers for considering this paper and your welcomed reviews), what I am probably addressing is 'aesthetic pleasure'. However, in order to 'fit' with Goéritz's Emotional Architecture concept, I have stayed with my original title.

As my research background is not in the area of Art and Cartography, I acknowledge that here I tread on dangerous ground. The reason for undertaking this research was to ascertain whether certain cartographic products may, when viewed, inspire viewers and uplift their emotions. This proposition needed to be tested by assessing a selection of cartographic artefacts against one Art theory. The theory papers from the era that was applied is Warehouse Theory.

\section{Overview}

Thinking about maps that inspire, or uplift, can some maps that, when viewed, do this? I embarked on a small research programme to try to discover whether some maps - analogue or digital - could do this. If they in fact could, can these be referred to as 'Emotion maps'?, the title of this paper.

What I don't mean is the concept that, just because a map 'looks' like a piece of art, or if it was developed with due reference to a particular art genre, this does not make the map 'art'. Take for example Harry Beck's London Underground Map. Looking at the map, it does somewhat resemble a piece of Piet Mondrian's art - white background and simple bold colour line work. But, does this make Beck's map 'art'? I consider the answer to this question to be 'no' (even though it is part of the V\&A's collection).

Addressing this differently, where an art genre is used as a 'template' with which to develop the general 'look-and-feel' of a map product. But is it (the map) art? Craig A Elimeliah's opinion (2006) is that the paths laid down by past artists establish a style ... when that style or method is used by another artist, the art then turns into design.

What I did was look at design areas outside the 'Art' world/discipline, see if some are the exemplar works from these disciplines could provide pathways, then see if they could be applied to maps. In so doing, I would firstly need to determine how the Art world defined itself.

'Art'

My quest to be 'informed' about 'Art' and emotions led me to manuscripts from the 1950s and 1960s, which were written in the same era as Goéritz proposed Emotional Architecture, which I believed was an appropriate approach. Therefore, this undertaking is founded on Art Theory from this era, rather than current thinking, which I also acknowledge would be problematic if I wanted this contribution to be adjudged for current Art Theory merit, which was not my quest.

I looked at what has been written, from the papers from this period. I accept that this is a distinct time period, and what the Art world now define 'Art' has moved on. Literature written about this question in the 1950s-1970s (Brunius, 1956; Ziff, 1953; Saw, 1961; Dickie, 1969; Ames, 1971; Danto, 1964; Weitz, 1956; Beardsley, 1961) defined Art under the headings of social/cultural context, critical acceptance, a human activity, artistic theory and aesthetics theory.

\section{Determining if (selected) maps can be considered to be art - Warehouse Theory}

Kennick (1958) proposes, as a useful, general, method for determining if an object is art, is Warehouse theory: 
"a person is directed to remove all the art objects from a huge warehouse which contains a great variety of things. The individual is able to select the art objects "with reasonable success" even though he employs no definition of art in terms of a common denominator. A work of art is known when seen. On the other hand, the same individual is at a loss when instructed to bring out all the expressive objects or all those which possess significant form, because the person does not recognize what expressiveness and significant form are".

I decided to use warehouse theory as a rudimentary method to determine, from a set of randomly selected maps. Stage one of this process was to ask the 80-100 participants at the BCS/SoC UK Mapping Festival, in London in September 2018, to view selected maps and, by a show of hands, state whether they thought that each map presented could, in their opinion, be considered to be Art (as per the Warehouse Theory). Twenty-two maps were shown to the audience, and their responses recorded. I acknowledge that this was a special 'Crowd', with a bias towards maps and mapping

The maps that were considered to be Art are listed below.

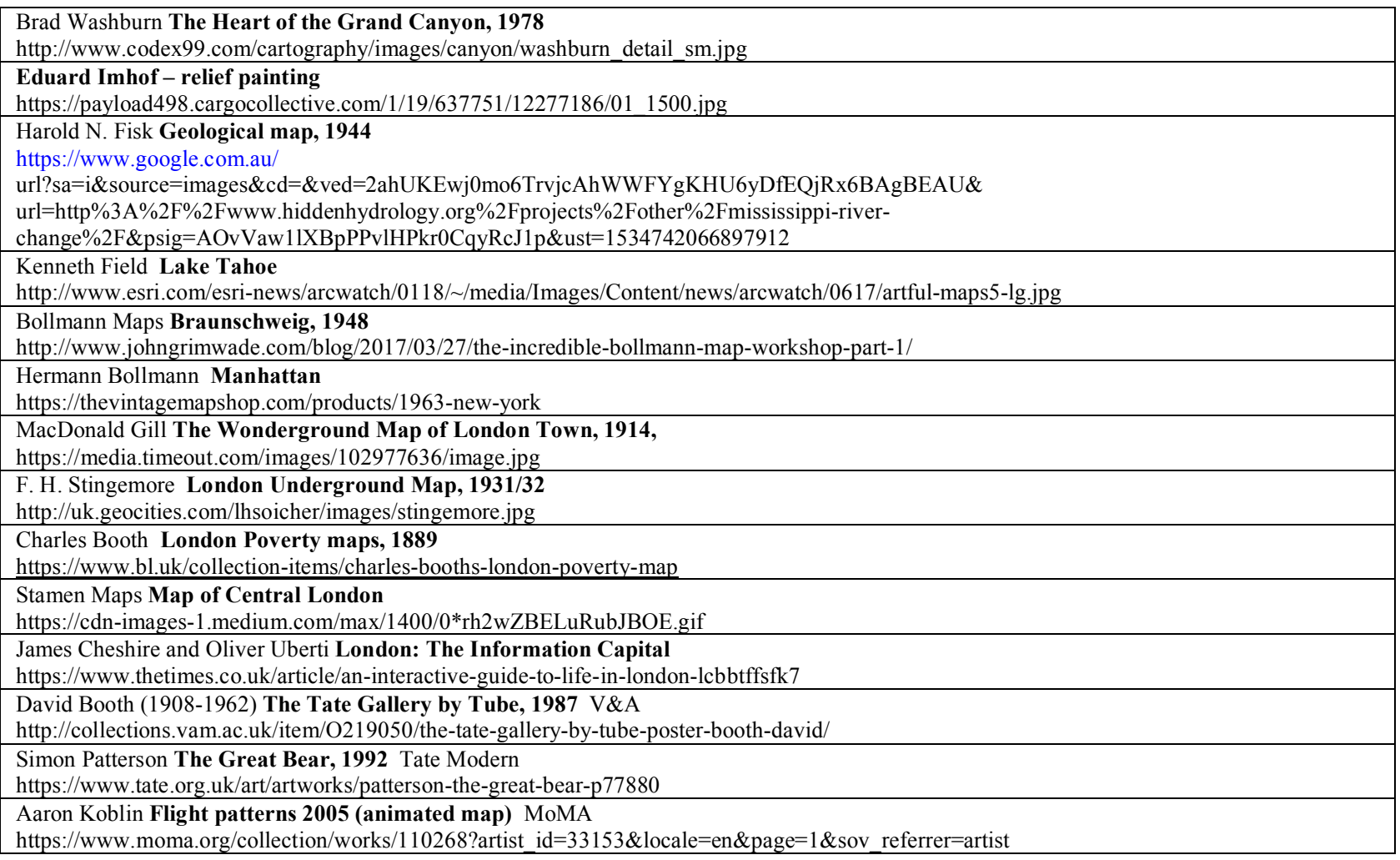

\section{Conclusion}

This contribution provides the thinking behind the survey of 'Maps as Art' using the Warehouse Theory. I acknowledge my niave approach to Art and Art Theory, and the limited overview of Art Theory employed. This paper reports on initial findings. Research is on-going.

\section{References}

Ames, V. M., 1971, “Is it Art?”, Journal of Aesthetics and Criticism, 30:39-48.

Beardsley, M. C., 1961, “On art and the definitions of arts: A symposium”, Journal of Aesthetics and Art Criticism; 20: 175-198.

Brunius, T., 1956, “The uses of works of art”, Journal of Aesthetics and Art Criticism"; 15: 35.

Danto, A., 1964, “The Artworld”, Journal of Philosophy; 61: 571-584.

Dickie, G., 1969, Defining Art, American Philosophical Quarterly, Vol. 6, No. 3 (Jul., 1969), pp. $253-256$.

http://www.jstor.org/stable/20009315 Accessed: 23-07-2018

Elimeliah, C. A., 2006, art Vs. design, AIGA Article, 13 January 2006. https://www.aiga.org/art-vs-design Accessed: 9-08-2018

Kennick, W. , 1958, Does Traditional Aesthetics Rest on a Mistake? Mind, 67(267), 317-334. Retrieved from http://www.jstor.org/stable/2251530 Accessed: 20-10-2018

Loiseau, B., 2017, 'Accidental Heroes', Wallpaper, Edition 223, October 2017, pp. 238-242.

Saw, R., 1961, What is a work of art?" Philosophy; 36: 39-48.

Weitz, M., 1956, The Role of Theory in Aesthetics, The Journal of Aesthetics and Art Criticism, Vol. 15, No. 1 (Sep., 1956), pp. 27-35. https://www.jstor.org/stable/427491 Accessed: 23-07-2018

Ziff, P., 1953, The Task of Defining a Work of Art, The Philosophical Review, Vol. 62, No. 1 (Jan., 1953), pp. 58-78. http://www.jstor.org/stable/2182722 Accessed: 23-07-2018 